\title{
First report of tobacco mosaic virus infecting Lagenaria siceraria (Molina) Standl. var. clavata Makino in China
}

\author{
Peng-Xiang Zhu ${ }^{1} \cdot$ Qi-Ping Zhang ${ }^{1} \cdot{\text { Zhao-Lin } \mathrm{Ji}^{1} \cdot \text { Feng Zhu }}^{1}$ \\ Received: 20 April 2020 / Accepted: 12 May 2020 / Published online: 18 May 2020 \\ (C) Società Italiana di Patologia Vegetale (S.I.Pa.V.) 2020
}

Keywords Tobacco mosaic virus $\cdot$ Lagenaria siceraria $\cdot$ China

Lagenaria siceraria (Molina) Standl. var. clavata Makino is an annual diploid plant of the family Cucurbitaceae. It is an economically important crop cultivated worldwide for vegetable production or medicinal purpose. In June 2019, viruslike symptoms, including foliar green-yellow mosaic, and mottling were observed on Lagenaria siceraria (Molina) Standl. var. clavata Makino in a greenhouse located in Yangzhou City, Jiangsu Province, East China. Leaf samples were collected from five symptomatic plants. All leaf samples were analyzed by Western blot using polyclonal antisera to tobacco mosaic virus (TMV) and cucumber mosaic virus (CMV) (Zhu et al. 2013). Three of five samples reacted positive to TMV but not to CMV. Next, we sequenced the open reading frame (ORF) of the movement protein (MP) of TMV. Total RNA was extracted from the three symptomatic leaf samples for RT-PCR using primers identical to nucleotides 4903 to 4922 (TMV-F: 5'-ATGGCTCTAGTTGTTAAAGG $-3^{\prime}$ ) and complementary to nucleotides 5690 to 5709 (TMV-R: 5'-TTAAAACGAATCCGATTCGG-3'), which were designed to amplify the complete movement protein region (GenBank Accession No. MK087763). The expected 807 bp amplicon was amplified from the three symptomatic leaf samples that were positive for TMV in Western blotting. RT-PCR products were purified and cloned into the pMD19-T vector (TaKaRa) (Zhu et al. 2018). Selected cDNA clones were sequenced (MT420733) and analyzed. BLASTn analysis indicated that the sequence showed $99.75-100 \%$ nucleotide

Peng-Xiang Zhu and Qi-Ping Zhang contributed equally to this work.

Feng Zhu

zhufeng@yzu.edu.cn

1 College of Horticulture and Plant Protection, Joint International Research Laboratory of Agriculture and Agri-Product Safety, the Ministry of Education of China, Yangzhou University,

Jiangsu 225009 Yangzhou, China identity to several TMV isolates for which sequences are available in GenBank (MK087763, JX993906, AB369276, AJ509081, KC007531). Nicotiana tabacum inoculated mechanically with sap from symptomatic Lagenaria siceraria (Molina) Standl. var. clavata Makino showed disease symptoms including green-dark green mosaic and distortion. TMV was detected in symptomatic $N$. tabacum by RT-PCR with the aforementioned primers. To our knowledge, this is the first report of TMV infecting Lagenaria siceraria (Molina) Standl. var. clavata Makino in China.

Acknowledgements This work was supported by the Qing Lan Project of Yangzhou University and the earmarked fund for Modern Agro-industry Technology Research System (CARS-30-3-02).

\section{Compliance with ethical standards}

Conflict of interest The authors declare that they have no conflict of interest.

Research involving human participants and/or animals This article does not contain any studies with human participants or animals performed by any of the authors.

Informed consent This manuscript is new and not being considered elsewhere. All authors have approved the submission of this manuscript.

\section{References}

Zhu F, Che YP, Liang ZJ, Ji ZL (2018) First report of tobacco rattle virus infecting spinach in China. Plant Dis 102:2671

Zhu F, Zhang P, Meng YF, Xu F, Zhang DW, Cheng J, Lin HH, Xi DH (2013) Alpha-momorcharin, a RIP produced by bitter melon, enhances defense response in tobacco plants against diverse plant viruses and shows antifungal activity in vitro. Planta 237:77-88

Publisher's note Springer Nature remains neutral with regard to jurisdictional claims in published maps and institutional affiliations. 